\title{
Health related quality of life in adolescents with chronic fatigue syndrome: a cross- sectional study
}

\author{
${\text { Anette Winger }{ }^{1 *} \text {, Gunnvald Kvarstein }{ }^{2} \text {, Vegard Bruun Wyller }}^{3,4,5}$, Mirjam Ekstedt ${ }^{7,8}$, Dag Sulheim ${ }^{4,6}$,
} Even Fagermoen ${ }^{3}$, Milada Cvancarova Småstuen ${ }^{1}$ and Sølvi Helseth ${ }^{1}$

\begin{abstract}
Aim: To study health related quality of life (HRQOL) and depressive symptoms in adolescents with chronic fatigue syndrome (CFS) and to investigate in which domains their HRQOL and depressive symptoms differ from those of healthy adolescents.

Background and objective: Several symptoms such as disabling fatigue, pain and depressive symptoms affect different life domains of adolescents with CFS. Compared to adolescents with other chronic diseases, young people with CFS are reported to be severely impaired, both physiologically and mentally. Despite this, few have investigated the HRQOL in this group.

Method: This is a cross-sectional study on HRQOL including 120 adolescents with CFS and 39 healthy controls (HC), between 12 and 18 years. The Pediatric Quality of Life Inventory ${ }^{\mathrm{TM}}, 4.0$ (PedsQL) was used to assess HRQOL. The Mood and Feelings Questionnaire assessed depressive symptoms. Data were collected between March 2010 and October 2012 as part of the NorCAPITAL project (Norwegian Study of Chronic Fatigue Syndrome in Adolescents: Pathophysiology and Intervention Trial). Linear and logistic regression models were used in analysis, and all tests were two-sided.
\end{abstract}

Results: Adolescents with CFS reported significantly lower overall HRQOL compared to HCs. When controlling for gender differences, CFS patients scored 44 points lower overall HRQOL on a scale from 0-100 compared to HCs. The domains with the largest differences were interference with physical health ( $\mathrm{B}=-59,95 \% \mathrm{Cl}-54$ to -65$)$ and school functioning ( $\mathrm{B}=-52,95 \% \mathrm{Cl}-45$ to -58$)$. Both depressive symptoms and being a patient were independently associated with lower levels of HRQOL

Conclusion: The difference in HRQOL between CFS patients and healthy adolescents was even larger than we expected. The large sample of adolescents with CFS in our study confirms previous findings from smaller studies, and emphasizes that CFS is a seriously disabling condition that has a strong impact on their HRQOL. Even though depressive symptoms were found in the group of patients, they could not statistically explain the poor HRQOL.

Keywords: adolescents, chronic fatigue syndrome, CFS/ME, health related quality of life, public health nurse, and pediatrics

\footnotetext{
* Correspondence: anette.winger@hioa.no

${ }^{1}$ Institute of Nursing, Faculty of Health Sciences, Oslo and Akershus University College of Applied Sciences, Postboks 4 St. Olavs plass, NO-0130 Oslo,

Norway

Full list of author information is available at the end of the article
}

\section{Biomed Central}

(c) 2015 Winger et al. This is an Open Access article distributed under the terms of the Creative Commons Attribution License (http://creativecommons.org/licenses/by/4.0), which permits unrestricted use, distribution, and reproduction in any medium, provided the original work is properly credited. The Creative Commons Public Domain Dedication waiver (http:// creativecommons.org/publicdomain/zero/1.0/) applies to the data made available in this article, unless otherwise stated. 


\section{Background}

Chronic fatigue syndrome (CFS) is a well-known, disabling and long-lasting condition with an estimated prevalence of $0.1 \%$ to $1.0 \%$ in children and adolescents (Nijhof et al. 2011, Crawley et al. 2011). The criteria from the Centers for Disease Control and Prevention (CDC), are most frequently used [1], and are also cited as the Fukuda-criteria. CFS is characterized by an unexplained disabling chronic or relapsing physical and mental fatigue of new onset lasting for more than six months, which is not relieved. It is combined with four or more of the eight specified accompanying symptoms: headache, muscle pain, joint pain, sore throat, tender lymph nodes, impaired memory or concentration, unrefreshing sleep, and malaise after exertion [1]. For children and adolescents, specific pediatric criteria have been introduced, requiring only three months of fatigue and only one additional symptom [2, 3]. Both pain and fatigue have great impact on physical activity [4], which again might act as a disease-maintaining factor [5]. Young people with CFS have reported more pronounced impairment, with reduced school attendance, compared with a corresponding sample of juvenile idiopathic arthritis [6]. This may be critical, as adolescents are in a vulnerable stage of life when social interaction with peers is highly important [7]. Depression is shown to be common in this group, but the causal relationship between CFS and depression is still unknown [8]. More important in this setting, anxiety and depression seem to be intensified by social isolation [9]. A previous qualitative study among healthy adolescents has shown that friends are one of the most important factors for HRQOL [10]. In the recent qualitative study from our group, the adolescents with CFS described a feeling of being different and forgotten when not being able to interact with friends or attend school [11]. CFS affects several life domains, and in adult CFS samples HRQOL has shown to be poor [12, 13]. However, few studies have thoroughly investigated the HRQOL perspective among adolescents with CFS. In a small study, including 25 children with CFS, Kennedy et al. [14] found that HRQOL was significantly more reduced compared with children and adolescents suffering from other chronic conditions.

Health-related quality of life (HRQOL) is a multidimensional construct consisting of different domains from physical, psychological, social and spiritual issues [15]. The functional capacity is affected in adolescents with CFS, but there is a lack of knowledge about physical impairment and how the impairments affect their HRQOL. When Kennedy et al. [14] assessed HRQOL among 25 children with CFS, they found physical health to be the most seriously affected domain. In other studies on this group, both physical and psychological functioning have been found to be particularly poor [16].
Our research group found that adolescents with CFS have a reduced level of activity measured as reduced number of steps daily [17]. This may have led to increased body mass index (BMI) [18] and poor physical quality of life [19].

The aims of this paper were to examine HRQOL and depressive symptoms in adolescents with CFS and to compare HRQOL and depressive symptoms with a group of healthy adolescents. We hypothesized that adolescents with CFS report lower HRQOL and have a higher degree of depressive symptoms compared to HCs.

\section{Material and methods \\ Design}

This is a cross-sectional study which describes HRQOL in adolescents with CFS and compares the HRQOL with a group of healthy adolescents. The study is part of the NorCAPITAL-project (The Norwegian Study of Chronic Fatigue Syndrome in Adolescents: Pathophysiology and Intervention Trial; Clinical Trials ID: NCT01040429) which explores possible mechanisms of CFS, the effect of low-dose clonidine treatment, and patients' experiences in adolescents with CFS [17].

\section{Study population \\ CFS patients}

One hundred and twenty adolescents with CFS and 39 healthy adolescents were recruited between March 2010 and October 2012. All pediatric departments in Norwegian hospitals $(n=20)$, as well as primary care pediatricians and general practitioners, were invited to refer adolescents with CFS (aged 12-18 years) to a central Norwegian department of pediatrics. The referring units were required to confirm that the patients did not have any medical or psychiatric disorder that might explain the fatigue. In agreement with clinical guidelines [2, 3] a "broad" case definition with three months of unexplained, disabling fatigue of new onset was required. We also required that the patient was not permanently bedridden and did not use pharmaceuticals (including hormone contraceptives) regularly. Those who fulfilled the pre-specified criteria for inclusion (Table 1), went through a thorough medical examination before they were invited to take part in the Nor CAPITAL study.

\section{A control group of healthy adolescents}

To recruit a control group of healthy adolescents, information about the study was sent to local schools. Those who replied, were given extended information. No regular use of pharmaceuticals (including hormones) was required to be included. A group of 39 healthy and normally active adolescents and comparable on gender and age, was enrolled. The HCs, however, were not actively matched. 
Table 1 Criteria for inclusion and exclusion

\begin{tabular}{|c|c|c|}
\hline & CFS patients & $\begin{array}{l}\text { Healthy control } \\
\text { subjects }\end{array}$ \\
\hline \multirow[t]{3}{*}{$\begin{array}{l}\text { Inclusion } \\
\text { criteria: }\end{array}$} & $\begin{array}{l}\text { Persisting or constantly relapsing } \\
\text { fatigue lasting } 3 \text { months or more. }\end{array}$ & \multirow[t]{3}{*}{$\begin{array}{l}\text { Age } \geq 12 \text { years } \\
\text { and }<18 \text { years }\end{array}$} \\
\hline & $\begin{array}{l}\text { Functional disability resulting from } \\
\text { fatigue to a degree that prevent } \\
\text { normal school attendance }\end{array}$ & \\
\hline & Age $\geq 12$ and $<18$ years & \\
\hline \multirow[t]{14}{*}{$\begin{array}{l}\text { Exclusion } \\
\text { criteria: }\end{array}$} & \multirow{2}{*}{$\begin{array}{l}\text { Another current process or chronic } \\
\text { disease or demanding life event } \\
\text { that might explain the fatigue }\end{array}$} & $\begin{array}{l}\text { Another chronic } \\
\text { disease }\end{array}$ \\
\hline & & $\begin{array}{l}\text { Permanent use of } \\
\text { pharmaceuticals } \\
\text { (including } \\
\text { hormones) }\end{array}$ \\
\hline & $\begin{array}{l}\text { Permanent use of pharmaceuticals } \\
\text { (including hormones) possibly } \\
\text { interfering with the measurements }\end{array}$ & \\
\hline & Permanently bed-ridden & \\
\hline & Positive pregnancy test & \\
\hline & Pheocromocytoma & \\
\hline & $\begin{array}{l}\text { Evidence of reduced cerebral and/or } \\
\text { peripheral circulation due to vessel } \\
\text { disease }\end{array}$ & \\
\hline & Polyneuropathy & \\
\hline & Renal insufficiency & \\
\hline & $\begin{array}{l}\text { Known hypersensitivity towards } \\
\text { clonidine or inert substances (lactose, } \\
\text { saccarose) in capsula }\end{array}$ & \\
\hline & Abnormal ECG (apart from ectopic beats) & \\
\hline & Supine heart rate $<50$ beats/min & \\
\hline & $\begin{array}{l}\text { Supine systolic blood pressure < } \\
85 \mathrm{mmHg}\end{array}$ & \\
\hline & $\begin{array}{l}\text { Upright systolic blood pressure } \\
\text { fall }>30 \mathrm{mmHg}\end{array}$ & \\
\hline
\end{tabular}

The criteria are designed for the randomized control trial in the NorCAPITALproject (The Norwegian Study of Chronic Fatigue Syndrome in Adolescents: Pathophysiology and Intervention Trial; Clinical Trials ID: NCT01040429), which explores possible mechanisms of CFS, the effect of low-dose clonidine treatment, and patients' experiences as adolescents with CFS (9)

\section{Measures}

\section{Body Mass Index}

Research in children and adolescents shows that overweight and obesity have impact on their HRQOL [20]. According to The Norwegian Directorate of Health [21], BMI is calculated as weight in kilograms divided by height in squared meters and is adjusted for age and gender. We decided to transform BMI into a categorical variable with three categories; $\mathrm{BMI}<25$ (normal weight), $25 \leq \mathrm{BMI}<30$, and $\mathrm{BMI} \geq 30$ (Table 1). Weight and height were measured by the researchers.

\section{PedsQL}

To measure HRQOL we used the Pediatric Quality of Life Inventory ${ }^{\mathrm{Tm}}, 4.0$ (PedsQL), which is a 23-item generic questionnaire developed to measure HRQOL in healthy children and adolescents, as well as in pediatric populations with acute and chronic health conditions [22]. The questions cover all the health domains stated by WHO including school functioning [23] and are suitable for children and adolescents aged between 5 and 18 years. Corresponding questionnaires for proxies exist (there are several versions dependent on age). The PedsQL provides a total sum score and four subscale scores in the following domains; (1) physical functioning (8 items), (2) emotional functioning (5 items), (3) social functioning (5 items), and (4) school functioning (5 items). Three of the subscales (emotional, social, and school functioning) are combined to provide a specific scale for psychosocial health. Participants are asked to rate the severity of each item during the previous month by a Likert Scale from 0 (never a problem) to 5 (a lot of a problem). Items are reversescored and linearly transformed on a scale ranging from $0-100(0=100,1=75,2=50,3=25,4=0)$, where higher scores indicate better HRQOL. Each subscale score is computed as the sum of points from each item divided by the number of items answered [23]. The instrument has been translated into several languages, among these Norwegian, and validated [24]. Scale internal consistency was measured with Cronbach's alpha, varying between 0.77 and 0.88 , which is considered good [24].

\section{The mood and feelings questionnaire}

Levels of depressive symptoms were identified using The Mood and Feelings Questionnaire (MFQ) which is validated for children and adolescents [25]. MFQ consists of 33 items with three alternative answers (not true $=0$, sometimes $=1$, true $=2$ ). Total score ranges from 0 to 66 . A score $\geq 20$ implies presence of depressive symptoms to a degree that suggests mood disorder [25], and was therefore chosen as the cutoff. MFQ has been used in several Norwegian studies [26-28], showing good internal consistency [26].

Also the PedsQL includes questions concerning depression-like symptoms. These questions, however, are phrased differently and cover slightly different areas compared to questions in MFQ. Moreover, the questions covering depressive symptoms, are to be scored differently, and represent only a part of the overall score. We thus found it meaningful to model associations between HRQOL and depressive symptoms.

\section{Ethical considerations}

The study was approved by the Norwegian Social Science Data Service and by the Norwegian Regional Committee for Medical and Health Research Ethics. Participation in the project required informed consent by the adolescent and by his or her parents/next-of-kin after written and oral information about the study. 


\section{Statistical analyses}

Continuous data (age and disease duration) are presented as means with $S D$ while categorical data (gender, parents' education and BMI) are presented as numbers and percentages. Differences between CFS patients and $\mathrm{HCs}$ were assessed with Chi-square test analyses for the independent categorical variables gender and BMI.

To further investigate the differences between CFS patients and $\mathrm{HCs}$, we fitted a linear regression model with overall HRQOL score and the sub-scores for each domain as dependent variables. We moreover adjusted for gender, depressive symptoms and categories of BMI. The factor BMI, however, did not reach statistical significance and was excluded from further analysis. The risk of having depressive symptoms (a dichotomized dependent variable) was modeled using logistic regression and adjusted for gender and BMI.

Both regression models fitted the data well (goodness of model fit), and all residuals were approximately normally distributed (linear regression). The results are presented as estimates of beta (B) with $95 \%$ confidence intervals (CI). The results of logistic regression are presented as odds ratios $(O R)$ with $95 \% \mathrm{CI}$. All tests were two-sided, and $P$-values $<0.05$ were considered statistically significant. All analyses were performed using IBM SPSS statistics version 21.

There were almost no missing data in any of the data sets. Values were imputed for individuals when less than $10 \%$ of the values were missing by using the mean score for each variable. Individuals who had more than $10 \%$ missing values in total, were excluded.

As a result of difficulties in recruitment of healthy controls, our sample of HCs was smaller than the group of adolescents with CFS. We therefore compared the average levels of the $\mathrm{HCs}$ with corresponding levels in the healthy population in the Norwegian validation study of the PedsQL [24], and the control group of HCs in the study by Diseth and coworkers [29] including children/ adolescents subjected to renal transplantation (TX) and children in remission after acute lymphoblastic leukemia (ALL). Confidence intervals were not available in these studies, but knowing the mean and $S D$, we could compute the CI making it possible to compare the data.

\section{Results}

In total, we included 120 adolescents with CFS and 39 healthy adolescents as controls. Participants were comparable regarding age (mean 15.4 for CFS patients and mean 15.2 for $\mathrm{HCs}$ ), and gender (72\% girls in both the CFS and $\mathrm{HC}$ group).

The comparison of our relatively small group of HCs with other studies using PedsQL to measure HRQOL in children, suggest that our sample of HCs is a representative control group (Table 2).

Almost all the patients had suffered from CFS for a long period of time (mean 21.4 months) (Table 3), and only two patients had a short disease duration of between three and six months.

As there was no difference between the CFS group and HCs concerning demographics such as parents' education (Table 3) and ethnicity (data presented elsewhere [17]), we did not need to adjust for these variables when assessing group differences. The CFS group had a slightly higher mean BMI, but the group difference did not reach statistical significance.

When adjusted for gender, CFS patients had significantly lower overall HRQOL than did the HCs (44 HRQOL points, $\mathrm{B}=-44,95 \% \mathrm{CI}(-39.6$ to -48.6$))$ (Table 4$)$, and for each subscale the group differences were even more pronounced; on a scale from $0-100$ it was 60 points lower for physical functioning, 52 points lower for school functioning, 28 points lower for emotional functioning, and 27 points lower for social functioning. Concerning psychosocial HRQOL, the CFS patients had on average 33 points lower scores than $\mathrm{HCs}$, independent of gender and BMI (Fig. 1 and Table 5).

Table 2 Comparing PedsQL results from the NorCAPITAL study with two other studies

\begin{tabular}{|c|c|c|c|c|c|c|c|c|c|c|c|c|}
\hline & \multicolumn{4}{|c|}{ NorCAPITAL study } & \multicolumn{2}{|c|}{$\begin{array}{l}\text { Reinfjell et al. } 2006 \\
\text { [24] }\end{array}$} & \multicolumn{2}{|c|}{$\begin{array}{l}\text { Diseth et al. } 2011 \\
\text { [29] }\end{array}$} & \multicolumn{2}{|c|}{$\begin{array}{l}\text { Diseth et al. } 2011 \\
\text { [29] }\end{array}$} & \multicolumn{2}{|c|}{$\begin{array}{l}\text { Diseth et al. } 2011 \\
\text { [29] }\end{array}$} \\
\hline & CFS & $95 \%$ & $\mathrm{HCs}$ & $95 \%$ & $\mathrm{HCs}$ & $95 \%$ & $\mathrm{HCs}$ & $95 \%$ & $\mathrm{TX}$ & $95 \%$ & $\mathrm{ALL}$ & $95 \%$ \\
\hline & Mean (SD) & & Mean (SD) & & Mean (SD) & & Mean (SD) & & Mean (SD) & & Mean (SD) & \\
\hline Variable & $N=120$ & & $N=39$ & & $N=425$ & & $N=42$ & & $N=38$ & & $N=40$ & \\
\hline Age & $12-18$ & & $12-18$ & & $13-15$ & & $3-19$ & & 3-19 & & $3-19$ & \\
\hline Overall QoL & $49(13)$ & $46-51$ & $93(8)$ & $89-96$ & $85(11)$ & $84-86$ & $89(8)$ & $87-91$ & $69(18)$ & $63-75$ & $82(13)$ & $78-86$ \\
\hline Physical health & $37(17)$ & $33-40$ & $96(8)$ & $92-99$ & $91(10)$ & $90-92$ & $92(6)$ & $90-94$ & $75(17)$ & $69-81$ & $86(12)$ & $82-90$ \\
\hline Emotional functioning & $60(18)$ & $56-63$ & $88(14)$ & 83-94 & $77(17)$ & $75-79$ & $83(13)$ & $79-87$ & $69(16)$ & $61-74$ & $75(19)$ & $69-81$ \\
\hline Social functioning & $70(15)$ & $68-73$ & $98(4)$ & $97-99$ & $88(13)$ & $87-89$ & $93(8)$ & $90-96$ & $74(22)$ & $67-81$ & $86(14)$ & $82-90$ \\
\hline School functioning & $36(19)$ & $33-39$ & $88(14)$ & $81-93$ & $78(15)$ & $77-79$ & $86(13)$ & $82-90$ & $63(18)$ & $57-69$ & $77(16)$ & $72-82$ \\
\hline Psychosocial functioning & $57(15)$ & $54-60$ & $91(10)$ & $88-96$ & $82(13)$ & $81-83$ & $87(9)$ & $84-90$ & $67(18)$ & $61-73$ & $79(14)$ & $75-83$ \\
\hline
\end{tabular}

HRQOL is assessed by PedsQL 
Table 3 Demographic data and adherence to the CDC-criteria for CFS

\begin{tabular}{|c|c|c|}
\hline & CFS patients & Controls \\
\hline & $N=120$ & $N=39$ \\
\hline Variable & n (\%) & n (\%) \\
\hline Male & $34(28)$ & $11(28.2)$ \\
\hline Female & $86(72)$ & $28(71.8)$ \\
\hline CDC criteria & $88(74)$ & NA \\
\hline Lives together with both parents & $85(73)$ & $26(70)$ \\
\hline \multicolumn{3}{|l|}{ BMI (adjusted for age and gender) } \\
\hline Normal weight (BMI <25) & $100(83.3)$ & $37(94.9)$ \\
\hline Moderate overweight $(25 \leq \mathrm{BMI}<30)$ & $14(11.7)$ & $2(5.1)$ \\
\hline Severe overweight (BMI $\geq 30$ ) & $6(5.0)$ & $0(0)$ \\
\hline MFQ (depressive symptoms) ${ }^{a}$ & $47(39)$ & $3(8)$ \\
\hline \multicolumn{3}{|l|}{ Parents highest education } \\
\hline Primary school & $5(4.3)$ & $0(0)$ \\
\hline Secondary school & $30(26)$ & $8(23)$ \\
\hline Lower university & $34(29)$ & $9(23)$ \\
\hline \multirow[t]{2}{*}{ Higher university } & $48(41)$ & $19(54)$ \\
\hline & Mean (SD) & Mean (SD) \\
\hline Age & $15.4(1.6)$ & $15.2(1.6)$ \\
\hline Disease duration (months) & $21.4(15.2)$ & NA \\
\hline School absence $\%{ }^{\mathrm{b}}$ & $65(30)$ & $2.1(6.8)$ \\
\hline
\end{tabular}

${ }^{a}$ MFQ (Mood and feelings Questionnaire) score $>20$ suggests depressive symptoms and was the cutoff chosen. NA = not applicable. ${ }^{\mathrm{b}} \mathrm{S}$ chool absence was calculated as the ratio between mean days absent from school last month and days supposed to be at school last month. These proportions are presented as mean values with SD

Figure 1 depicts point-estimates for HRQOL for CFS patients and controls with standard errors of the mean values for sum-score and sub-scores for each domain. The estimates show a high precision due to the high number of CFS patients and the homogeneity of the control group. The specific values are presented in Table 5.

Table 4 Comparison of health related quality of life between adolescents with CFS and HCs

\begin{tabular}{lllll}
\hline Variable & Items & Estimate of B & $95 \% \mathrm{Cl}$ & $p$-value \\
\hline Overall HRQOL & 23 & -44 & $(-49 ;-40)$ & $<0.001$ \\
Physical health & 8 & -60 & $(-54 ;-66)$ & $<0.001$ \\
Emotional functioning & 5 & -28 & $(-22 ;-35)$ & $<0.001$ \\
Social functioning & 5 & -27 & $(-22 ;-33)$ & $<0.001$ \\
School functioning & 5 & -52 & $(-45 ;-58)$ & $<0.001$ \\
Psychosocial functioning & 15 & -36 & $(-31 ;-41)$ & $<0.001$ \\
\hline
\end{tabular}

HRQOL was assessed by the Pediatric Quality of Life Inventory ${ }^{\mathrm{Tm}}, 4.0$ (PedsQL). The listed estimates express the difference between adolescents with CFS and healthy controls. Multiple linear regression for total score and subscale scores are adjusted for gender differences between the groups. CFS: $N:=114$, HHCs: $N=36$
Regarding gender differences, girls (both adolescents with CFS and $\mathrm{HCs}$ ) demonstrated a 5 points lower overall HRQOL level $(\mathrm{B}=-4.7,95 \% \mathrm{CI}(-8.9$ to -0.5$))$ compared to boys. This was also the case for the subscales physical health $(\mathrm{B}=-5.9,95 \% \mathrm{CI}-11.3$ to -0.5$)$ and emotional functioning ( $\mathrm{B}=-7.3,95 \% \mathrm{CI}-13.4$ to -1.3$)$.

Logistic regression analysis indicated an eight times higher risk of depressive symptoms when having CFS compared to $\mathrm{HCs}(\mathrm{OR}=7.9,95 \% \mathrm{CI} 2.3-27.4)$. When modeling quality of life using linear regression, higher levels of depressive symptoms were inversely associated with higher levels of HRQOL both in CFS patients and in HCs. Further, we modelled HRQOL with multiple linear regression. When depressive symptoms was entered as a covariate, we only uncovered an additive effect of depressive symptoms and no interaction between having a higher level of depressive symptoms and being a CFS patient. Thus having a higher level of depressive symptoms was associated with the same change of effect on HRQOL in CFS patients and HCs, and the strength and size of the association between being a CFS patients and HRQOL were not changed when adjusted for depressive symptoms. We therefore conclude that both depressive symptoms and being a patient were independently associated with lower levels of HRQOL.

\section{Discussion}

Our findings show that adolescents with CFS have a significantly lower quality of life compared with healthy controls, demonstrated by lower overall HRQOL score and sub-score levels for specific HRQOL domains. Depressive symptoms were found in both adolescents with CFS and HCs, but the score levels were higher among the adolescents with CFS. The low HRQOL level in the CFS group was not explained by depressive symptoms but by having CFS.

\section{Health related quality of life and depressive symptoms}

This is the first large study investigating HRQOL in adolescents with CFS. Both overall HRQOL and the subscalescores for different life domains were lower compared to $\mathrm{HCs}$, in line with the results from a smaller, previous study which included 25 adolescents with CFS [14]. The group differences in our study were not explained by gender, BMI or socio-demographic differences.

Although depressive symptoms is found to be the main predictor for reduction in daily functioning in adults with CFS [30], the cause effect relation between CFS and depression is still debated [8]. Skapinskis et al., studying an adult population, proposed that depression might lead to CFS [31], while Bould and coworkers, on the contrary, suggested that the experience of having CFS could explain depressive traits in adolescents with CFS [32]. The CFS patients in our sample showed an 


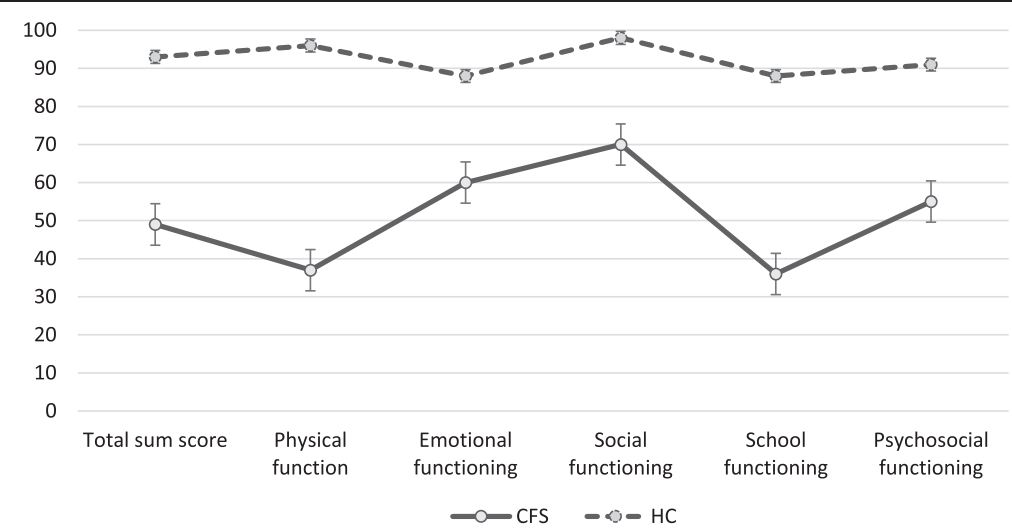

Fig. 1 Health Related Quality of Life among Adolescents with CFS and Healthy Controls. (Detailed Legend Fig. 1): HRQOL was assessed by the Pediatric Quality of Life Inventory ${ }^{\mathrm{TM}}$, 4.0 (PedsQL). Total score and subscales scores are presented by mean values and SD. CFS: N: $=114, \mathrm{HCs}$ : N = 34

eight times higher risk of having a mood disorder, but a higher level of depressive symptoms had statistically the same effect on HRQOL in both groups. Our model showed that having depressive symptoms and having CFS independently explained the low HRQOL scores. Thus, being a CFS patient was an independent factor explaining the lower HRQOL, and it was not confounded by depressive symptoms.

We chose a low cut-off indicating mood disorders and not a clinical relevant cut-off screening for major depression. This might be the reason for the relatively high proportion of HCs $(8 \%)$ with depressive symptoms.

\section{Emotional functioning}

On emotional functioning, our CFS population scored 60 out of maximum 100 points; 30 points lower than the group of healthy adolescents. Even though we used a different questionnaire, the results are almost equal to Kennedy et al. who found 54 points out of 100 on emotional function. Alexithymia, which means difficulties in experiencing, expressing, and describing emotional responses, has been suggested as a factor in the

Table 5 Health related quality of life among adolescents with CFS and HCS

\begin{tabular}{|c|c|c|}
\hline & Scores, Mean (SD) & Scores, Mean (SD) \\
\hline & Adolescents with CFS & Healthy Controls \\
\hline & $(n=114)$ & $(n=36)$ \\
\hline Overall HRQOL ${ }^{a}$ & $48.8(13.0)$ & $92.9(8.2)$ \\
\hline Physical health & $36.5(17.2)$ & $96.0(8.1)$ \\
\hline Emotional functioning & $59.8(18.2)$ & $88.1(14.0)$ \\
\hline Social functioning & $70.0(15.1)$ & $97.8(3.9)$ \\
\hline School functioning & $36.0(18.8)$ & $87.6(13.9)$ \\
\hline Psychosocial functioning ${ }^{b}$ & $55.4(13.1)$ & $91.2(8.9)$ \\
\hline
\end{tabular}

HRQOL was assessed by the Pediatric Quality of Life Inventory ${ }^{\mathrm{Tm}}, 4.0$ (PedsQL) a Sum score of all questions. ${ }^{b}$ Combined score of emotional, social and school functioning. Total score and subscales scores are presented as mean values with SD development of medically unexplained diseases such as CFS. In a study by van de Putte et al. [33], however, alexithymia did not correlate as a unique factor to CFS and did not appear as a prognostic factor for recovery from CFS. A study by Garralda \& Rangel [6] has shown that children with CFS use more emotional regulation or resignation and fewer problem-solving strategies to deal with disabilities compared with other children. Experiencing difficult thoughts and sad feelings (depressive symptoms) might not be surprising, considering the consequences of the disease, such as reduced school attendance and time with peers. Thus, it should be of importance to support the adolescents in handling sad and difficult feelings.

\section{Physical functioning}

Despite the sparse number of studies on HRQOL in adolescents, those which are available address domains like physical impairment and school attendance [34, 4, 35]. It should be borne in mind that physical health in PedsQL includes both physical activity, the feeling of low energy, and pain as an unpleasant bodily symptom [23], as they are all interconnected. Low mood and fatigue are associated with worse physical function and are the strongest predictors for school absence [4].

The fact that physical health and school functioning were most affected in our sample, might not be surprising considering the nature of CFS. Garralda and Rangel (2004) have demonstrated that children (10-18 years) with CFS are even more impaired compared with children with juvenile idiopathic arthritis (9-18), especially when it comes to schoolwork, expectations and attendance. This was also the case when compared with children with type 1 diabetes and asthma [14]. We further compared our findings (Table 2) with a recent Norwegian study on HRQOL including children and adolescents subjected to renal transplantation (TX) (with a median age since transplantation at 4.9 years), and children in remission after 
acute lymphoblastic leukemia (ALL) [29]. Our study suggests that adolescents with CFS were even more interfered by their illness than adolescents with renal TX and ALL. We have previously reported that our CFS patients performed a significantly lower number of steps per day [17], suffered from more severe pain, and had a lower pressure pain threshold than HCs [36]. The low activity among CFS patients might stem from the feeling of extreme fatigue and/or activity-related pain. When experiencing malaise and pain after even normal activity, patients may easily develop a fair avoidance behavior [35] as demonstrated among adults with CFS [37]. Gray and Rutter [38] identified two important factors for predicting physical functioning in adolescents with CFS: adolescents who adapted to the illness (using Leventhal's self-regulation model measuring) reported a better quality of life, and those who managed to maintain some degree of activity reported better physical outcomes. A stronger focus on symptoms was by contrast associated with poorer HRQOL. The authors suggested that adapting to the illness might act as a mediator, leading to better coping strategies.

\section{School functioning as a factor for social interaction}

In our study, school functioning was the most affected HRQOL domain, with a score level (Fig. 1, Table 3) substantially lower compared with previous studies on CFS patients $[14,39,6]$. In a qualitative study, recently published, we explored adolescents' own experience of living with CFS, and found that lack of participation at school and in teen venues made them feel like outsiders [11]. This is a serious finding, considering that a good relation to friends is one of the most important factors for HRQOL in healthy adolescents [10]. Other studies on adolescents with CFS have similarly emphasized the need for friends as an important factor for well-being $[9,40]$. The adolescents with CFS experienced loss of a normal life, and the changes in friendships as difficult, leading to loneliness and isolation [9].

School is surely an institution for learning and intellectual activities, but is also an arena for socializing. Previously, we have reported that some of the adolescents managed to shift focus from friends and school towards other arenas like their family, and appreciated their support [11]. Thus, relational factors within the family seem to be even more important for children with CFS than those with other chronic conditions [41]. In this way, however, adolescents with CFS might become even more dependent on care-givers [35] which may hinder growing towards independence. This dilemma underpins the importance of involving the family in treatment. The dramatic changes following low school functioning may have serious educational and social implications [4]. A study on school drop-outs in adolescents with chronic somatic diseases found an increased risk of sickness and disabilities later in young adulthood [42]. To minimize school drop-out and the risk of long term consequences, the authors pointed to the importance of early intervention.

\section{HRQOL and gender differences}

Looking at gender difference, the overall scores of HRQOL were lower among girls compared to boys, both in the CFS and the HC group. Gender differences have also been demonstrated in previous HRQOL studies [24] and are not unique in adolescents with CFS.

\section{Strengths and limitations}

The Nor CAPITAL study had one clear selection bias, as the study included only patients who were able to attend our research clinic; and the results can therefore not be extrapolated to the most seriously affected CFS adolescents. Secondly, the number of HCs in our study was only one third compared to the group of CFS patients. We therefore additionally compared the average levels of the $\mathrm{HCs}$ with corresponding levels from the healthy population in the Norwegian validation study of the PedsQL [24] and the control group of HCs in a study by Diseth and coworkers [29] (Table 2). The comparison with the other studies suggest that our sample of HCs is a representative control group.

Validating MFQ, Daviss et al. [25] suggested two different cutoffs which differentiate between depressive symptoms (cutoff $\geq 20$ ), and major depression (cutoff $\geq 29$ ). The relatively high proportion of patients with depressive symptoms in our study might be explained by the low cutoff value. Although depressive symptoms were only found to have an additive effect on HRQOL, this does not change the fact that adolescents with CFS report seriously poor HRQOL.

\section{What this study adds}

The large study population contributes to underpin an area almost not studied and documented in this population. The study provides new knowledge about how bad the life of these adolescents are, and their HRQOL was even poorer than we expected. The poor HRQOL was explained by the illness and not by depressive symptoms. The relatively large study population with few missing data makes it possible to generalize the findings.

\section{Conclusion}

The large sample of adolescents with CFS in our study confirms previous findings from smaller studies and emphasizes that CFS is a seriously disabling condition that has strong impact on their HRQOL. Compared to healthy adolescents, HRQOL in adolescents with CFS was even poorer than we expected, and physical function and school function showed the lowest sub-scores. Even though depressive symptoms were found in the group of 


\section{patients, they could not statistically explain the poor HRQOL.}

\section{Competing interests}

The authors declare that they have no competing interests.

\section{Authors' contributions}

ME conceptualized and designed the study and critically revised the manuscript for important intellectual content and approved the final manuscript as submitted. EF conceptualized and designed the study, acquired data and critically revised the manuscript for important intellectual content and approved the final manuscript as submitted. SH conceptualized and designed the study, analyzed and interpreted data, drafted the manuscript, critically revised the manuscript for important intellectual content, obtained funding and approved the final manuscript as submitted. GK conceptualized and designed the study, analyzed and interpreted data, drafted the manuscript, critically revised the manuscript for important intellectual content and approved the final manuscript as submitted. MCS analyzed and interpreted data, carried out the statistical analyzes, critically revised the manuscript for important intellectual content and approved the final manuscript as submitted. DS conceptualized and designed the study, acquired data and critically revised the manuscript for important intellectual content and approved the final manuscript as submitted. AW conceptualized and designed the study, acquired data, analyzed and interpreted data, drafted the manuscript and critically revised the manuscript for important intellectual content, carried out the statistical analyzes, obtained funding and approved the final manuscript as submitted. VBW conceptualized and designed the study, critically revised the manuscript for important intellectual content, obtained funding and approved the final manuscript as submitted. All authors read and approved the final manuscript.

\section{Acknowledgments}

Kari Gjersum provided secretarial assistance, Berit Widerøe Niølstad, MA; Adelheid Holm, RN; Marianne Svendsen, BSc; Anne Marie Halstensen, RN; Kristin Villa, RN; Esther Gangsø, BSc; Hamsana Chandrakumar, BSc and Anna Marie Thorendal Ryenbakken provided practical assistance.

\section{Author details}

${ }^{1}$ Institute of Nursing, Faculty of Health Sciences, Oslo and Akershus University College of Applied Sciences, Postboks 4 St. Olavs plass, NO-0130 Oslo, Norway. ${ }^{2}$ Department of Clinical Medicine, UIT The Arctic University of Norway, Tromso, Norway. Institute of Clinical Medicine, Medical Faculty, University of Oslo, Oslo, Norway. ${ }^{4}$ Department of Pediatrics, Oslo University Hospital, Oslo, Norway. ${ }^{5}$ Department of Pediatrics, Akershus University Hospital, Lørenskog, Norway. ${ }^{6}$ Department of Pediatrics, Innlandet Hospital Trust, Lillehammer, Norway. ${ }^{7} \mathrm{KTH}$, Royal Institute of Technology, School for Technology and Health, Stockholm, Sweden. ${ }^{8}$ Center for Shared Decision Making and Collaborative Care, Oslo University Hospital, Oslo, Norway.

\section{Received: 21 March 2015 Accepted: 17 June 2015}

\section{Published online: 03 July 2015}

\section{References}

1. Fukuda K, Straus SE, Hickie I, Sharpe MC, Dobbins JG, Komaroff A. The chronic fatigue syndrome: a comprehensive approach to its definition and study. Ann Intern Med. 1994;121(12):953.

2. Royal College of Paediatrics and Child Health. Evidence based guidelines for the management of CFS/ME (chronic fatigue syndrome/myalgic encephalopathy) in children and young adults. London: Royal College of Paediatrics and Child Health 2004; 2004.

3. National Institute of Health and Care Excelence. Chronic fatigue syndrome/myalgic encephalomyelitis (or encephalopathy): Diagnosis and management of CFS/ME in adults and children. 2007.

4. Crawley E, Sterne JA. Association between school absence and physical function in paediatric chronic fatigue syndrome/myalgic encephalopathy. Arch Dis Child. 2009;94(10):752-6.

5. Rangel L, Garralda ME, Levin M, Roberts $H$. The course of severe chronic fatigue syndrome in childhood. J R Soc Med. 2000;93(3):129-34.

6. Garralda ME, Rangel L. Impairment and coping in children and adolescents with chronic fatigue syndrome: a comparative study with other paediatric disorders. J Child Psychol Psychiatry. 2004;45(3):543-52. doi:10.1111/j.1469-7610.2004.00244.x.

7. Frisen A. Measuring health-related quality of life in adolescence. Acta Paediatrica. 2007;:96(7):pp. doi:10.1111/j.1651-2227.2007.00333.x 17498184.

8. Bould H, Collin SM, Lewis G, Rimes K, Crawley E. Depression in paediatric chronic fatique syndrome. Arch Dis Child. 2013;98(6):425-8. doi:10.1136/archdischild-2012-303396.

9. Fisher H, Crawley E. Why do young people with CFS/ME feel anxious? A qualitative study. Clin Child Psychol Psychiatry. 2013;18(4):556-73. doi:10.1177/1359104512460862

10. Helseth S, Misvaer N. Adolescents' perceptions of quality of life: what it is and what matters. J Clin Nurs. 2010;19(9-10):1454-61.

11. Winger A, Ekstedt M, Wyller VB, Helseth S. 'Sometimes it feels as if the world goes on without me': adolescents' experiences of living with chronic fatigue syndrome. J Clin Nurs. 2013. doi:10.1111/jocn.12522.

12. Hardt J, Buchwald D, Wilks D, Sharpe M, Nix WA, Egle UT. Health-related quality of life in patients with chronic fatigue syndrome: an international study. J Psychosom Res. 2001;51(2):431-4.

13. Lowry TJ, Pakenham KI. Health-related quality of life in chronic fatigue syndrome: predictors of physical functioning and psychological distress. Psychol Health Med. 2008;13(2):222-38. doi:10.1080/13548500701335698.

14. Kennedy G, Underwood C, Belch JJ. Physical and functional impact of chronic fatigue syndrome/myalgic encephalomyelitis in childhood. Pediatrics. 2010;125(6):e1324-30. doi:10.1542/peds.2009-2644.

15. Eiser $C$, Morse $R$. The measurement of quality of life in children: past and future perspectives. J Dev Behav Pediatr. 2001;22(4):248-56.

16. Torres-Harding SR, Jordan K, Jason LA, Arias R. Psychosocial and physical impact of chronic fatigue in a community-based sample of children and adolescents. J Chronic Fatigue Syndr. 2006;13(2-3):55-74. doi:10.1300/J092v13n02_03.

17. Sulheim D, Fagermoen E, Winger A, Andersen AM, Godang K, Muller F, et al. Disease mechanisms and clonidine treatment in adolescent chronic fatigue syndrome: a combined cross-sectional and randomized clinical trial. JAMA Pediatr. 2014. doi:10.1001/jamapediatrics.2013.4647.

18. Lievesley K, Rimes KA, Chalder T. A review of the predisposing, precipitating and perpetuating factors in chronic fatigue syndrome in children and adolescents. Clin Psychol Rev. 2014;34(3):233-48. doi:10.1016/j.cpr.2014.02.002.

19. Swallen KC, Reither EN, Haas SA, Meier AM. Overweight, obesity, and health-related quality of life among adolescents: the National Longitudinal Study of Adolescent Health. Pediatrics. 2005;115(2):340-7.

20. Buttitta M, lliescu C, Rousseau A, Guerrien A. Quality of life in overweight and obese children and adolescents: a literature review. Qual Life Res. 2014;23(4):1117-39.

21. The Norwegian Directorate of Health. Norwegian clinical guideline for prevention, assessment and treatment of overweight and obesity in children and adolescents. In: Health TNDo, editor. Oslo, Norway2010.

22. Varni JW, Seid M, Rode CA. The PedsQLTM. Measurement model for the Pediatric Quality of Life Inventory. Feb 1999. Medical Care. 1999;37(2):pp. doi:10.1097/00005650-199902000-00003 10024117.

23. Varni J, Seid M, Kurtin P. PedsQL (TM) 4.0: Reliability and validity of the pediatric quality of life Inventory (TM) Version 4.0 generic core scales in healthy and patient populations. Med Care. 2001;39(8):800-12.

24. Reinfjell T, Diseth T, Veenstra M, Vikan A. Measuring health-related quality of life in young adolescents: Reliability and validity in the Norwegian version of the Pediatric Quality of Life InventoryTM 4.0 (PedsQL) generic core scales. Health and Quality of Life Outcomes. 2006;4(1):61.

25. Daviss WB, Birmaher B, Melhem NA, Axelson DA, Michaels SM, Brent DA. Criterion validity of the Mood and Feelings Questionnaire for depressive episodes in clinic and non-clinic subjects. J Child Psychol Psychiatry. 2006;47(9):927-34. doi:10.1111/j.1469-7610.2006.01646.x

26. Sund AM, Larsson B, Wichstrom L. Depressive symptoms among young Norwegian adolescents as measured by the Mood and Feelings Questionnaire (MFQ). Eur Child Adolesc Psychiatry. 2001;10(4):222-9.

27. Sund AM, Larsson B, Wichstrom L. Psychosocial correlates of depressive symptoms among 12-14-year-old Norwegian adolescents. J Child Psychol Psychiatry. 2003:44(4):588-97.

28. Sund AM, Larsson B, Wichstrom L. Prevalence and characteristics of depressive disorders in early adolescents in central Norway. Child Adolesc Psychiatry Ment Health. 2011;5:28. doi:10.1186/1753-2000-5-28. 
29. Diseth TH, Tangeraas T, Reinfjell T, Bjerre A. Kidney transplantation in childhood: mental health and quality of life of children and caregivers. Pediatr Nephrol. 2011;26(10):1881-92. doi:10.1007/s00467-011-1887-9.

30. Meeus M, Nijs J, Van Mol E, Truijen S, De Meirleir K. Role of psychological aspects in both chronic pain and in daily functioning in chronic fatigue syndrome: a prospective longitudinal study. Clin Rheumatol. 2012;31(6):921-9. doi:10.1007/s10067-012-1946-z.

31. Skapinakis $P$, Lewis $G$, Mavreas $V$. Temporal relations between unexplained fatigue and depression: longitudinal data from an international study in primary care. Psychosom Med. 2004;66(3):330-5.

32. Bould H, Lewis G, Emond A, Crawley E. Depression and anxiety in children with CFS/ME: cause or effect? Arch Dis Child. 2011;96(3):211-4. doi:10.1136/adc.2009.173161

33. van de Putte EM, Engelbert RHH, Kuis W, Kimpen JLL, Uiterwaal CSPM. Alexithymia in adolescents with chronic fatigue syndrome. J Psychosom Res. 2007;63(4):377-80.

34. Richards J. Chronic Fatigue Syndrome in Children and Adolescents: A Review Article. Clin Child Psychol Psychiatry 2000 2000;5(31). doi:10.1177/1359104500005001005.

35. Garralda EM, Chalder T. Practitioner review: chronic fatigue syndrome in childhood. J Child Psychol Psychiatry. 2005;46(11):1143-51. doi:10.1111/j.1469-7610.2005.01424.x.

36. Winger A, Kvarstein G, Wyller VB, Sulheim D, Fagermoen E, Småstuen MC et al. Pain and pressure pain thresholds in adolescents with chronic fatigue syndrome and healthy controls: a cross-sectional study. BMJ Open. 2014;4(10). doi:10.1136/bmjopen-2014-005920.

37. Vercoulen JH, Swanink CM, Fennis JF, Galama JM, van der Meer JW, Bleijenberg G. Dimensional assessment of chronic fatigue syndrome. J Psychosom Res. 1994;38(5):383-92.

38. Gray SE, Rutter DR. IIIness representations in young people with Chronic Fatigue Syndrome. Psychology \& Health. 2007;.22(2):pp. doi:10.1080/14768320600774595.

39. Bell DS, Robinson M, Jordan K. Thirteen-year follow-up of children and adolescents with chronic fatigue syndrome. Pediatrics. 2001;107(5):994

40. Jelbert R, Stedmon J, Stephens A. A qualitative exploration of adolescents' experiences of chronic fatigue syndrome. Clin Child Psychol Psychiatry. 2010;15(2):267-83. doi:10.1177/1359104509340940.

41. Rangel L, Garralda ME, Jeffs J, Rose G. Family health and characteristics in chronic fatigue syndrome, juvenile rheumatoid arthritis, and emotional disorders of childhood. J Am Acad Child Adolesc Psychiatry. 2005;44(2):150-8. doi:10.1097/00004583-200502000-00007.

42. De Ridder KA, Pape K, Cuypers K, Johnsen R, Holmen TL, Westin S, et al. High school dropout and long-term sickness and disability in young adulthood: a prospective propensity score stratified cohort study (the Young-HUNT study). BMC Public Health. 2013;13:941. doi:10.1186/1471-2458-13-941.

\section{Submit your next manuscript to BioMed Central and take full advantage of:}

- Convenient online submission

- Thorough peer review

- No space constraints or color figure charges

- Immediate publication on acceptance

- Inclusion in PubMed, CAS, Scopus and Google Scholar

- Research which is freely available for redistribution 